\title{
The glucagonoma syndrome and necrolytic migratory erythema: a clinical review
}

\author{
André P van Beek, Ellen R M de Haas ${ }^{1}$, Willem A van Vloten ${ }^{2}$, Cees J M Lips ${ }^{3}$, Janine F M Roijers ${ }^{3}$ and \\ Marijke R Canninga-van Dijk ${ }^{4}$ \\ University Medical Center Groningen, Department of Endocrinology, PO Box 30.001, 9700 RB, Groningen, ${ }^{1}$ Erasmus MC - University Medical Center \\ Rotterdam, Department of Dermatology, PO Box 1738, 3000 DR, Rotterdam, and Departments of ${ }^{2}$ Dermatology, ${ }^{3}$ Endocrinology and ${ }^{4}$ Pathology, \\ University Medical Center Utrecht, PO Box 85.500, 3508 GA, Utrecht, The Netherlands
}

(Correspondence should be addressed to A P van Beek; Email: a.p.van.beek@int.azg.nl)

\begin{abstract}
The glucagonoma syndrome is a rare disease in which a typical skin disorder, necrolytic migratory erythema, is often one of the first presenting symptoms. Weight loss and diabetes mellitus are two other prevalent characteristics of this syndrome. Necrolytic migratory erythema belongs to the recently recognized family of deficiency dermatoses of which zinc deficiency, necrolytic acral erythema and pellagra are also members. It is typically characterized on skin biopsies by necrolysis of the upper epidermis with vacuolated keratinocytes. In persistent hyperglucagonemia, excessive stimulation of basic metabolic pathways results in diabetes mellitus at the expense of tissue glycogen stores, and muscle and fat mass. Multiple (essential) nutrient and vitamin B deficiencies develop, which contribute to the dermatosis. In addition, glucagonomas may produce various other products, like pancreatic polypeptide, that add to the catabolic effects of glucagon.
\end{abstract}

European Journal of Endocrinology 151 531-537

\section{Introduction}

In 1942 Becker et al. (1) described a patient with a typical skin disorder who was found to have a pancreatic neoplasm. More than 20 years later, McGavran et al. (2) documented hyperglucagonemia in association with the cutaneous eruptions. The combination of symptoms was called the glucagonoma syndrome. The typical skin lesions were called necrolytic migratory erythema by Wilkinson $(3,4)$. Here, we describe two patients with markedly elevated glucagon concentrations due to a glucagonoma; however, only one patient presented the glucagonoma syndrome. We focus on the skin disorder, a characteristic deficiency dermatosis, and compare it with similar skin disorders. Diagnostic considerations from dermatological and endocrine perspectives are given. Further, we discuss the metabolic consequences of hyperglucagonemia in relation to the characteristic dermatological and pathophysiological findings in this disease.

\section{Patient 1}

A 67-year-old man was referred to the Department of Dermatology of the University Medical Center Utrecht because of an extensive, itching cutaneous eruption that had been present for 18 months. His medical history revealed that at age 20 he had an appendectomy and at age 50 he was operated on because of bilateral inguinal herniae. His medical history was otherwise unremarkable and he was receiving no medication. The skin eruption started at his lower extremities and progressed to involve trunk, upper extremities, head and neck. It had been present with waxing and waning and migrated along the body surface. In addition to the skin problem our patient complained of weight loss (10 kg in 1 year), weakness and a burning mouth. The family history was negative for multiple endocrine neoplasia or diabetes mellitus.

On physical examination, the patient appeared cachectic (weight, $69 \mathrm{~kg}$; height, $183 \mathrm{~cm}$ ). Along the body surface were cutaneous eruptions of erythematous polycyclic migratory lesions with advancing scaling borders. The centers were hypopigmented or slightly scaly. The chronic lesions showed hyperpigmentation and scaling more than erythema (Fig. 1). Some of the older lesions were crustated (Fig. 2). The patient had a glossy red tongue (Fig. 3); lungs, heart and abdomen were normal. The neurological examination was unremarkable and no visual field defects were found.

Extensive laboratory testing revealed a normocytic anemia (hemoglobin, $7.2 \mathrm{mmol} / \mathrm{l}$ ). Blood chemistries and electrolytes were all normal, except for a random glucose concentration of $13.6 \mathrm{mmol} / \mathrm{l}$.

A biopsy of the skin (Fig. 4) showed vacuolated keratinocytes in the upper epidermis leading to confluent necrosis of the epithelium. There was a mild 


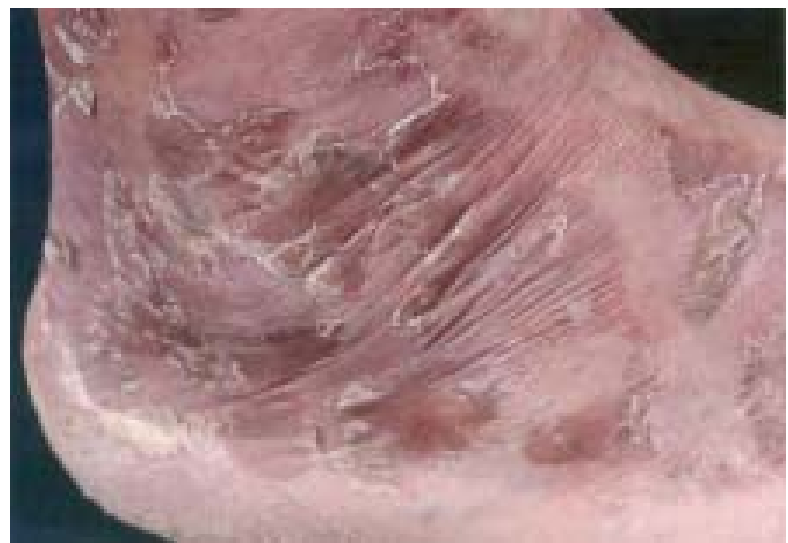

Figure 1 Necrolytic migratory erythema with typical scaling, erythema and hyperpigmentation.

infiltrate of lymphocytes in the superficial dermis. The histological findings on skin biopsy were compatible with the diagnosis of necrolytic migratory erythema and prompted further diagnostic work-up for a pancreatic islet cell tumor. Abdominal ultrasonography showed a process in the tail of the pancreas.

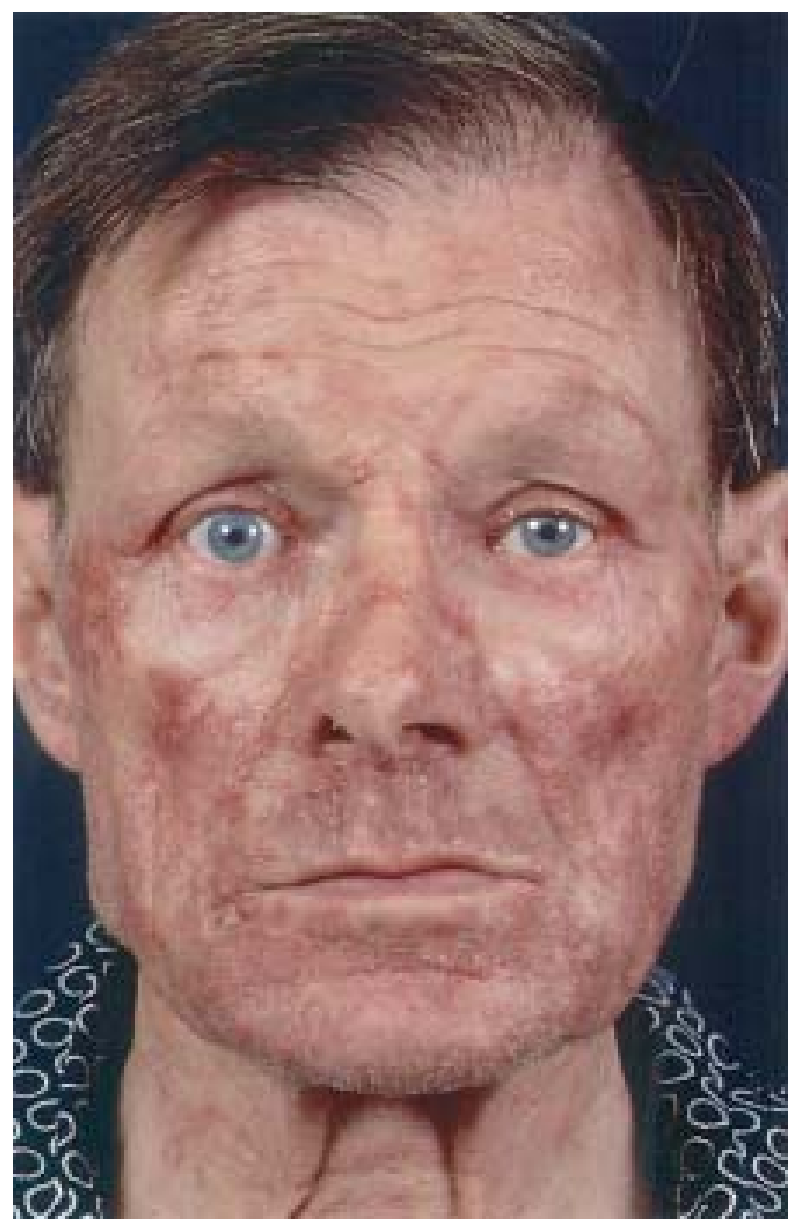

Figure 2 Necrolytic migratory erythema in the face with older crustated lesions (with permission of patient).
The patient was subsequently referred to the endocrinology department on suspicion of having the glucagonoma syndrome. An abdominal computed tomography scan reported a large pancreatic mass with a diameter of $13 \mathrm{~cm}$ (Fig. 5). No evidence of metastases in the liver or elsewhere was found.

Hormone analyses showed that both glucagon levels (700 pmol/l; normal, $14-40 \mathrm{pmol} / \mathrm{l})$ and pancreatic polypeptide $(6000 \mathrm{pmol} / \mathrm{l}$; normal, $<100 \mathrm{pmol} / \mathrm{l})$ were grossly elevated. An octreotide test $(100 \mu \mathrm{g}$ s.c.) was performed and resulted in strong suppression of both hormones.

Treatment was initiated with somatostatin, and surgical removal of the glucagonoma was subsequently performed in our hospital by distal pancreatectomy. During the operation there were no signs of lymph node involvement or other metastases. On histological examination the pancreas showed an islet cell tumor with a size of $14 \mathrm{~cm}$. There was vaso-invasive growth of tumor cells. The peri-pancreatic lymph nodes were negative. Immuno-histochemical stainings showed the tumor to be positive for glucagon, synaptophysine and chromogranine. Genetic analysis of the glucagonoma

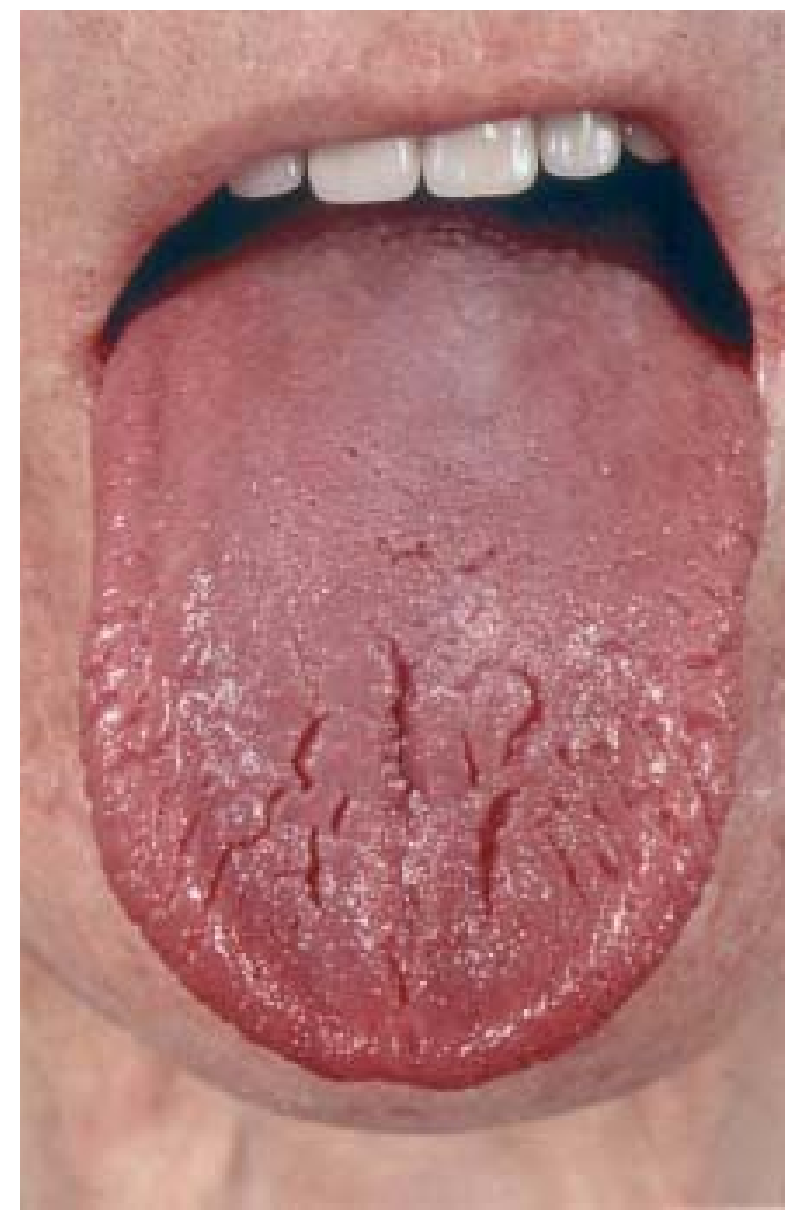

Figure 3 Glossitis in the glucagonoma syndrome. 


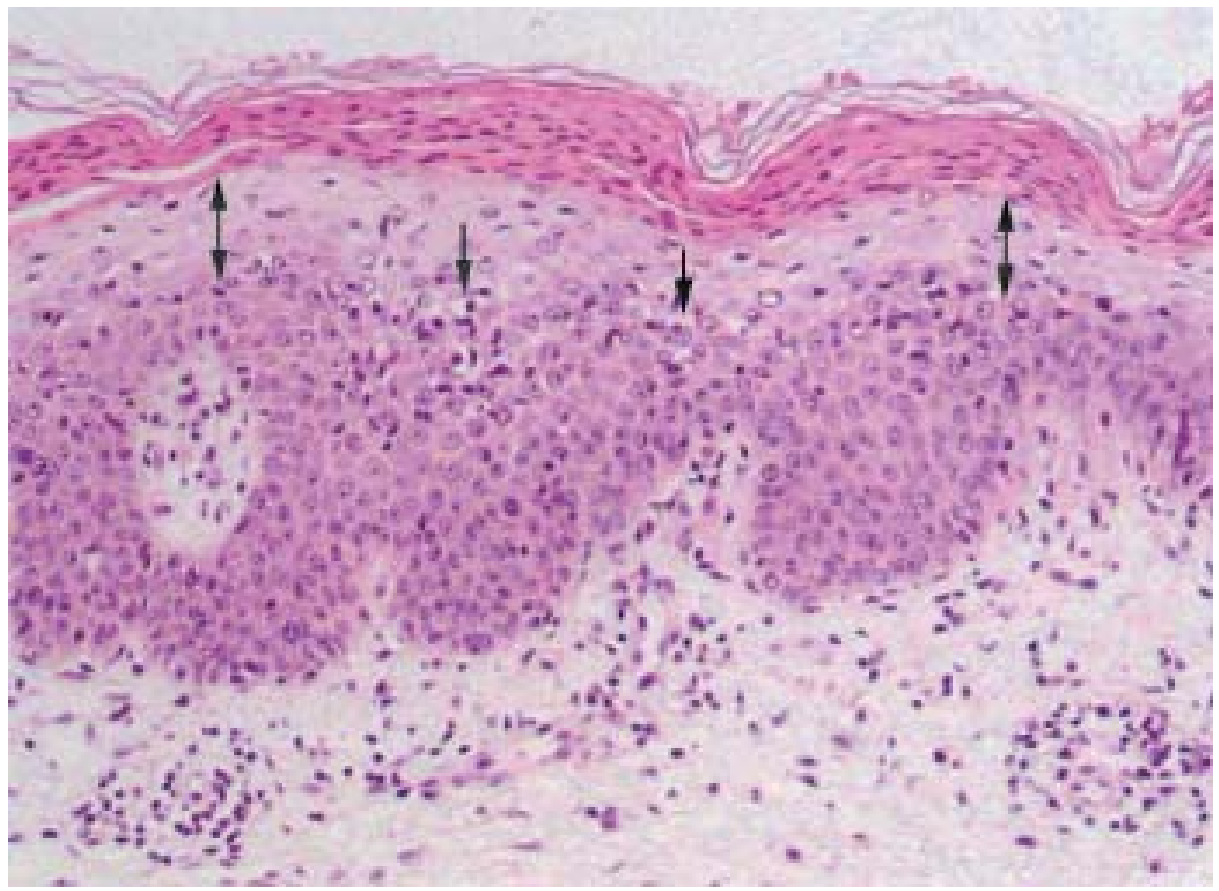

Figure 4 Skin biopsy in necrolytic migratory erythema showing a large zone of necrolysis in the upper epidermis (double headed arrows) and vacuolated keratinocytes (single headed arrows).

revealed no mutation of the multiple endocrine neoplasia type-1 (MEN1) gene.

Postoperatively, the necrolytic migratory erythema disappeared almost immediately. After 1 week no sign of skin disease was left. The glucagon concentrations returned to normal values $(19 \mathrm{pmol} / \mathrm{l})$ within 1 week, and remained normal. Nineteen months after surgical treatment, a slight increase in pancreatic polypeptide level (118 pmol/l) was found, while the other hormone levels were still normal. Five months later, the patient complained of weakness in his legs. Magnetic imaging revealed a tumor at the level of thoracic vertebrae 8 to 11. Needle biopsy showed a neuro-endocrine tumor, most probably a relapse of the glucagonoma

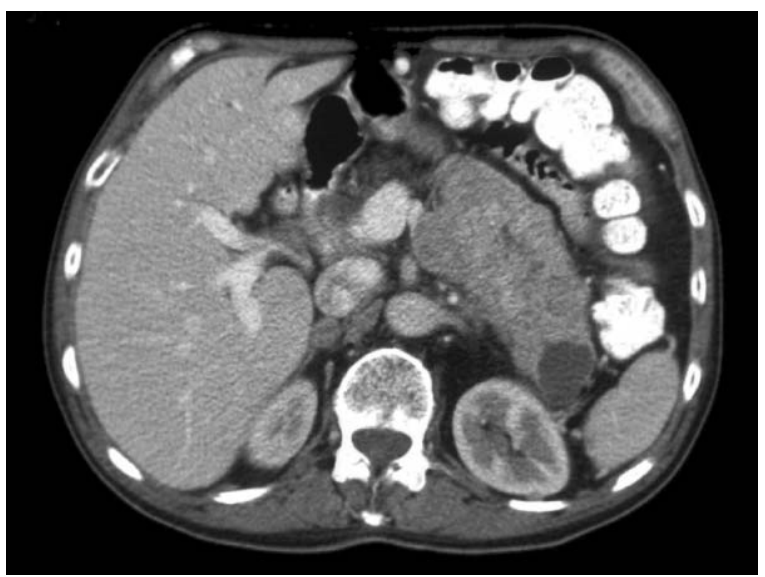

Figure $5 \mathrm{CT}$ scan of the abdomen of patient 1, revealing a large tumor in the tail of the pancreas. although the glucagon level was still normal. Within a few weeks our patient was not able to walk alone. Shortly thereafter he was found dead at home. Autopsy was not performed.

\section{Patient 2}

A 16-year-old boy was found to have hyperglucagonemia (145 pmol/l; normal, $14-40 \mathrm{pmol} / \mathrm{l})$ during regular screening visits at our outpatient clinic. He is a carrier of a mutation in the MEN1 gene and comes from a family with MEN1. His father suffered from Cushing's syndrome and died at the age of 39 due to the consequences of Zollinger-Ellison syndrome. His brother had recurrent epileptic insults at age 13, due to an insulinoma.

He had no complaints and his physical examination, with special attention to skin problems, was unremarkable. An abdominal magnetic resonance imaging scan and angiography showed a mass with a diameter of $2 \mathrm{~cm}$ in the corpus of the pancreas. Because of potential malignancy a subtotal pancreatectomy was performed. Histological examination revealed multiple islet cell tumors positively staining for insulin, glucagon and pancreatic polypeptide. Plasma concentrations of insulin were not increased. Pancreatic polypeptide levels were not determined. As a consequence of the MEN1 syndrome he developed hyperparathyroidism and the Zollinger-Ellison syndrome. Currently, 15 years after removal of the glucagonoma, he is in good health. 


\section{Discussion}

We have described two patients with distinctly elevated glucagon concentrations but only one had the glucagonoma syndrome. Thus, glucagonoma producing islet cell tumors can present with various clinical manifestations ranging from asymptomatic (patient 2) to the full-blown glucagonoma syndrome (patient 1). The most common features of this syndrome are weight loss, the necrolytic migratory erythema and diabetes mellitus (5). The prognosis of this disease varies greatly according to the stage at which the disease is diagnosed. Early recognition of the symptoms of the glucagonoma syndrome is therefore important (6). Glucagonomas due to MEN1 syndrome are rare and comprise not more than 3\% of the glucagonomas (7). They probably carry a better prognosis due to early recognition by periodic screening visits $(8,9)$. Sporadic cases are diagnosed much later in the course of the disease. By the time of diagnosis, 50\% (10) to $100 \%$ (5) of patients already present with metastatic disease and a cure is often impossible. The tumor is resistant to chemotherapy and metastatic disease is often not amenable to surgical resection (11). However, since this island cell tumor is slow growing, prolonged survival (more than 20 years) is possible (12) and in metastatic disease most causes of death appear to be unrelated to the tumor (5). Successful palliative treatment is possible with long-acting somatostatin analogs (13) and/or interferon alpha (14). In addition, supplementation with zinc, amino acids and essential fatty acids appears to be beneficial in some cases $(15-17)$ together with topical dermatological therapy (10). We will now focus on the challenge of diagnosing the glucagonoma syndrome from two points of view.

\section{The dermato-pathologic perspective}

Necrolytic migratory erythema: characteristics of a deficiency dermatosis The necrolytic migratory erythema is the presenting problem in roughly $70 \%$ of the patients with a glucagonoma (5). The lesions consist of an intense erythema with superficial epidermal necrosis. This leads to shedding of the skin with flaccid bullae and crusted erosions. Central healing occurs, which gives the lesions an annular appearance. The lesions primarily affect the perineum and other intertriginous sites. The trunk, legs, perioral skin and sites of minor trauma can also be involved. Onychoschizia is reported (12). The most specific feature on histological examination of the skin, is necrolysis of the upper epidermis with vacuolated keratinocytes, leading to focal or confluent necrosis (18). In fact, the histology of the skin is very similar to the biopsy findings in other deficiency states like pellagra (19), zinc deficiency (20) and necrolytic acral erythema (21). We will discuss these conditions because they are the histopathological differential diagnosis of necrolytic migratory erythema.

Pellagra Pellagra develops as a consequence of inadequate amounts of niacin (nicotinic acid) in the tissues. It is a multi-system nutritional disorder resulting from a primary dietary deficiency, malabsorption, use of chemotherapeutic agents, or from abnormalities of tryptophan metabolism $(22,23)$. An example of this latter category is the carcinoid syndrome, in which tumor cells divert tryptophan metabolism toward serotonin and away from nicotinic acid. In Hartnup disease there is a congenital defect in tryptophan absorption and transfer. Initially, there is a burning erythema in sun-exposed areas. The lesions are sharply demarcated and have a symmetrical distribution. Particularly affected are the dorsum of the hands, the forearms, the face and the neck; blistering may occur. The final stage of the lesions is an intense hyperpigmentation with sharp margination and areas of epithelial desquamation. Other features include glossitis and angular cheilitis, comparable with lesions in the glucagonoma syndrome. Pellagra is sometimes called the 'disease of the four Ds': dermatitis, diarrhea, dementia and, if untreated, death.

Zinc deficiency Zinc deficiency usually presents in infancy. The cutaneous lesions are eczematous, crusted, sometimes vesico-bullous or pustular eruptions with an acral and periorificial distribution. The skin lesions are accompanied by alopecia and diarrhea. This recessively inherited condition, due to a rare disorder of zinc metabolism, is known as acrodermatitis enteropathica and may occasionally present itself in adulthood (24). Stomatitis, photophobia, nail dystrophy, hair shaft abnormalities, short stature and emotional disturbances can also be seen. Other causes of an acrodermatitis-enteropathica-like eruption are zinc deficiency in advanced cancer and in Crohn's disease, intestinal bypass procedures, gastrectomy, advanced alcoholic cirrhosis, the acquired immunodeficiency syndrome, isoleucine deficiency, anorexia nervosa, cystic fibrosis and artificial feeding in premature infants. This condition is rarely seen in breast-fed infants. Low body stores of zinc and a poor capability to absorb zinc from the gut make premature infants more vulnerable to the development of zinc deficiency than full-term infants. An acrodermatitis-enteropathica-like dermatosis is also described in patients with parenteral nutrition without zinc supplementation. The rare aminoacidopathies (methylmalonic and propionic acidemia) may cause a periorificial dermatitis resembling acrodermatitis enteropathica. Biotin deficiency, which can be due to an inborn error in metabolism such as biotinidase deficiency, can also mimic zinc deficiency.

Necrolytic acral erythema A variant of necrolytic erythema is the so-called necrolytic acral erythema, 
presenting with erythematous patches with erosions and blisters; there is a predilection for the lower limbs. Zinc levels are normal. This condition is strongly associated with hepatitis $C(21)$ and responds to treatment with interferon alpha and oral zinc.

In conclusion, when a dermato-pathologist notes the characteristic vacuolization of keratinocytes in the upper epidermis, he should think of the deficiency dermatoses mentioned above. If a clinical description or, even better, a clinical differential diagnosis including one of the deficiency states is given, it is possible to differentiate between the different types. However, frequently the condition will not be recognized by the clinicians and in these cases the best conclusion is: 'Biopsy of the skin suggestive for a deficiency dermatosis. Are there clinical indications for necrolytic migratory erythema, pellagra or zinc deficiency?'

\section{The endocrine perspective}

Diagnostic considerations Our first patient presented with cachexia, normocytic anemia, diabetes mellitus and a process in the tail of the pancreas. The differential diagnosis of pancreatic tumors includes, among other factors: pancreatic carcinoma, islet cell tumors (e.g. insulinoma or gastrinoma), abscesses or metastases. The combination of diabetes mellitus and a pancreatic tumor (especially in the tail of the pancreas) should prompt the clinician to think of an endocrine tumor. Although diabetes mellitus can develop as a consequence of a pancreatic carcinoma in $50 \%$ of cases, one should also think of glucagon- or somatostatin-producing tumors. The somatostatinoma syndrome consists of diabetes mellitus, cholecystolithiasis and steatorrhea (25); skin manifestations have not been described. Impaired fasting glycemia or diabetes mellitus is found in $80 \%$ of patients with the glucagonoma syndrome. As mentioned before, a typical skin disorder is part of this disease. Without having knowledge of a pancreatic process, recognition of the glucagonoma syndrome largely depends on appreciation of the skin disorder by clinician or pathologist. However, in most cases of the glucagonoma syndrome other potentially diagnostic clues are present. In our first patient weight loss and anemia were suggestive of neoplastic disease. Thus, careful radiological examination in the diagnostic work-up would eventually have revealed a pancreatic tumor. Furthermore, one should keep in mind that the development of diabetes in a patient without obesity can be the consequence of an endocrinopathy.

The hormonal origins and metabolic effects Glucagon and the glucagon-like peptides are encoded within a larger precursor, proglucagon. The proglucagon gene is expressed in the pancreas (A cells), intestine (L cells) and brain (solitary tract), giving rise to a single proglucagon mRNA transcript that is identical in all tissues. Tissue-specific post-translational processing of proglucagon accounts for the different molecular forms of the glucagon-related peptides present in each tissue $(26,27)$. In the pancreas it gives rise to glucagon, the major proglucagon fragment (MPGF) and glicentinrelated polypeptide. In the intestine, proglucagon peptide cleavage results in glicentin, oxyntomodulin and the glucagon-like peptides I and II (26). Hypoglycemia, most amino acids, many gut hormones and the autonomous nervous system promote pancreatic glucagon secretion directly or indirectly. Hyperglycemia, insulin and somatostatin exert an inhibitory influence. Glucagonomas secrete a disproportionate amount of proglucagon-like material (28-31).

Glucagon has various important effects on glucose, fat and protein metabolism (Fig. 6). It stimulates hepatic gluconeogenesis and inhibits glucose breakdown (glycolysis); glycogen synthesis is inhibited. In adequately fed people, glucagon also promotes glycogen breakdown (glycogenolysis) in the liver. In adipose tissue it activates hormone-sensitive lipase, the ratelimiting step in triglyceride degradation. Thus, it increases the free fatty acid delivery for hepatic

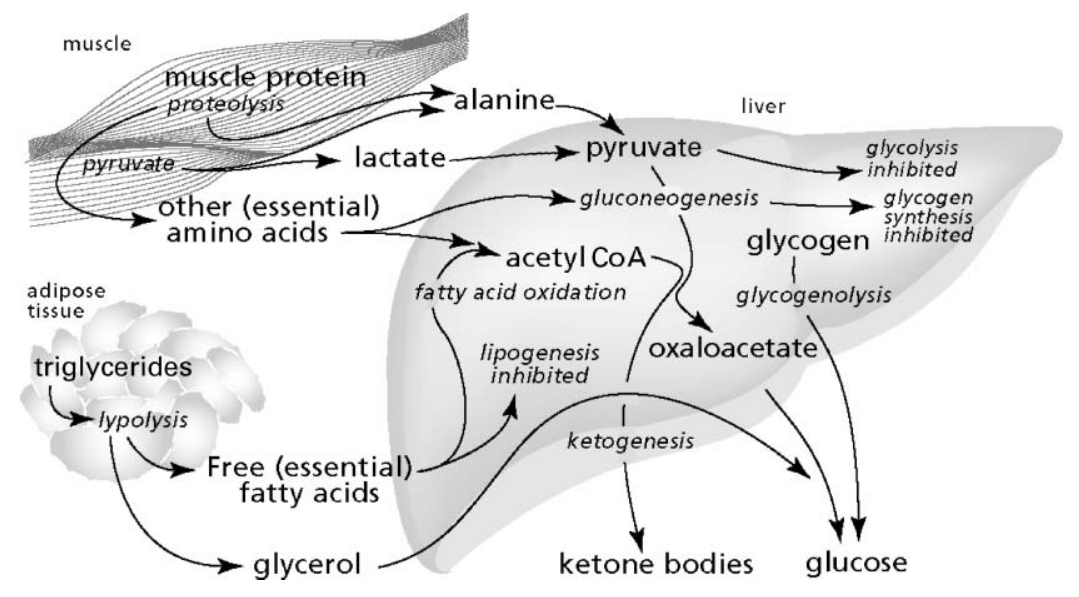

Figure 6 Metabolic effects of persistent hyperglucagonemia. 
ketogenesis while, at the same time, blocking liverderived lipoprotein production. In muscle, enhanced protein breakdown results in the flow of the gluconeogenic amino acids alanine and glutamine from muscle to liver. Urea synthesis in patients is increased (32). Hyperglucagonemia in healthy subjects and in the glucagonoma syndrome reduces plasma amino acid concentrations and enhances essential amino acid catabolism (32-35). As a consequence, in persistent hyperglucagonemia diabetes mellitus develops at the expense of tissue glycogen stores, muscle and fat mass.

The etiology of the necrolytic migratory erythema The exact cause of the skin rash remains unknown. Normalization of glucagon concentrations by surgery or somatostatin analogs almost invariably results in rapid disappearance of the skin disorder. Studies on treatment of various nutritional deficiencies have yielded limited success. However, it is likely from the physiological function of glucagon, as well as from the histopathological findings on tissue biopsy, that the necrolytic migratory erythema is a true deficiency dermatosis. Hypovitaminosis B develops through persistent stimulation of the carbohydrate metabolism as a result of hyperglucagonemia. Indeed, the glucagonoma syndrome exhibits several features of vitamin $\mathrm{B}_{2}$ (riboflavin) deficiency (angular stomatitis, cheilosis and glossitis), vitamin $\mathrm{B}_{3}$ (niacin) deficiency (dermatitis, diarrhea and dementia), vitamin $\mathrm{B}_{6}$ (pyridoxine) deficiency (disturbances in amino acid metabolism, hypochromic microcytic anemia, secondary pellagra; also exhibited are disturbances in the central nervous system like depression and convulsions) and panthothenic acid (pigmentation disorders), biotin (dermatitis), folic acid and vitamin $\mathrm{B}_{12}$ (cyanocobalamin) deficiencies (macrocytic anemia, neurological symptoms and dermatitis). Interestingly, relatively few symptoms have been described that suggest vitamin $\mathrm{B}_{1}$ (thiamine) deficiency - such as heart failure or Wernicke-Korsakoff syndrome. Furthermore, enhanced lipolysis may lead to deficiencies of essential fatty acids, which have been reported to result in a dermatitis with scaly lesions (36). Enhanced protein breakdown leads to essential amino acid deficiency which may result in a deficit of dopamine, (epi)nephrine, thyroxine, tri-iodothyronine and serotonin. All this may contribute in a complex way to the glucagonoma syndrome. Furthermore, post-translational processing may be different in pancreatic islet cell tumors, resulting in several bioactive polypeptides such as the glucagon-like peptides 1 and 2 , with profound effects on carbohydrate metabolism, intestinal motility and food intake (37-40). Pancreatic polypeptide is very often co-secreted in glucagonomas, as was the case in patient 1. Pancreatic polypeptide has known actions in gastrointestinal motility and secretion (41) and has recently been found to also inhibit food intake and stimulate energy expenditure following peripheral administration (42). Thus, high levels of pancreatic polypeptide and other proglucagon fragments may be important additional factors in the appearance of the glucagonoma syndrome, potentiating the catabolic effects of glucagon. However, hyperglucagonemia by itself is also sufficient for the development of necrolytic migratory erythema as evidenced by recent case reports of iatrogenic necrolytic migratory erythema after intravenous administration of glucagon in the treatment of persistent hypoglycemia (43-45). Perhaps, as in the carcinoid syndrome, systemic and not portal concentrations of glucagon are determinants of disease symptoms.

In conclusion, hyperglucagonemia provokes multiple nutrient and vitamin $\mathrm{B}$ deficiencies, which in turn are the probable cause of this typical skin disorder. Deficiencies may develop depending on the duration and degree of hyperglucagonemia and on the (pre-existing) nutritional status of the patient. In addition, other bioactive polypeptides may be co-secreted, potentially adding to the effects of glucagon. These factors all may contribute to the variable clinical expression of the glucagonoma syndrome.

\section{References}

1 Becker SW, Kahn D \& Rothman S. Cutaneous manifestations of internal malignant tumors. Archives of Dermatology and Syphilology $1942 \mathbf{4 5} 1069-1080$.

2 McGavran MH, Unger RH \& Recant L. A glucagon-secreting alpha-cell carcinoma of the pancreas. New England Journal of Medicine $19662741408-1413$.

3 Wilkinson DS. Necrolytic migratory erythema with carcinoma of the pancreas. Transactions of the St John's Hospital Dermatological Society $1973 \mathbf{5 9} 244-250$.

4 Wilkinson DS. Necrolytic migratory erythema with pancreatic carcinoma. Proceedings of the Royal Society of Medicine 197164 1197.

5 Wermers RA, Fatourechi V, Wynne AG, Kvols LK \& Lloyd RV. The glucagonoma syndrome. Clinical and pathologic features in 21 patients. Medicine 199675 53-63.

6 Edney JA, Hofmann S, Thompson JS \& Kessinger A. Glucagonoma syndrome is an underdiagnosed clinical entity. American Journal of Surgery $1990 \mathbf{1 6 0} 625-628$.

7 Wermers RA, Fatourechi V \& Kvols LK. Clinical spectrum of hyperglucagonemia associated with malignant neuroendocrine tumors. Mayo Clinic Proceedings 199671 1030-1038.

8 Akerstrom G, Hessman O \& Skogseid B. Timing and extent of surgery in symptomatic and asymptomatic neuroendocrine tumors of the pancreas in MEN 1. Langenbeck's Archives of Surgery 2002 $386558-569$.

9 Geerdink E, Van der Luijt RB \& Lips CJ. Do patients with multiple endocrine neoplasia syndrome type 1 benefit from periodical screening? European Journal of Endocrinology 2003149 577-582.

10 Stacpoole PW. The glucagonoma syndrome: clinical features, diagnosis, and treatment. Endocrine Reviews 19812 347-361.

11 Rosenberg PM \& Goldfinger SE. Glucagonoma and the glucagonoma syndrome. In UptoDate 2004 online 11.3.

12 Nightingale KJ, Davies MG \& Kingsnorth AN. Glucagonoma syndrome: survival 24 years following diagnosis. Digestive Surgery $19991668-71$.

13 Altimari AF, Bhoopalam N, O’Dorsio T, Lange CL, Sandberg L \& Prinz RA. Use of a somatostatin analog (SMS 201-995) in the glucagonoma syndrome. Surgery 1986100 989-996. 
14 Faiss S, Pape UF, Bohmig M, Dorffel Y, Mansmann U, Golder W, Riecken EO \& Wiedenmann B. Prospective, randomized, multicenter trial on the antiproliferative effect of lanreotide, interferon alfa, and their combination for therapy of metastatic neuroendocrine gastroenteropancreatic tumors - the International Lanreotide and Interferon Alfa Study Group. Journal of Clinical Oncology $2003212689-2696$.

15 Alexander EK, Robinson M, Staniec M \& Dluhy RG. Peripheral amino acid and fatty acid infusion for the treatment of necrolytic migratory erythema in the glucagonoma syndrome. Clinical Endocrinology $2002 \mathbf{5 7} 827-831$.

16 Bewley AP, Ross JS, Bunker CB \& Staughton RC. Successful treatment of a patient with octreotide-resistant necrolytic migratory erythema. British Journal of Dermatology $1996 \mathbf{1 3 4}$ 1101-1104.

17 Chastain MA. The glucagonoma syndrome: a review of its features and discussion of new perspectives. American Journal of the Medical Sciences 2001321 306-320.

18 Binnick AN, Spencer SK, Dennison WL Jr \& Horton ES. Glucagonoma syndrome. Report of two cases and literature review. Archives of Dermatology 1977113 749-754.

19 Haneke E. Acquired zinc deficiency mimicking glucagonoma dermatitis. Histology and electron microscopy. Zeitschrift fur Hautkrankheiten 198459 902-908.

20 Hoitsma HF, Cuesta MA, Starink TM, Uttendorfsky-van der Putten HJ \& van der Veen EA. Zinc deficiency syndrome versus glucagonoma syndrome. Archivum Chirurgicum Neerlandicum $197931131-140$.

21 El Darouti M \& Abu eE. Necrolytic acral erythema: a cutaneous marker of viral hepatitis C. International Journal of Dermatology $199635252-256$.

22 Hendricks WM. Pellagra and pellagra like dermatoses: etiology, differential diagnosis, dermatopathology, and treatment. Seminars in Dermatology $1991 \mathbf{1 0} 282-292$.

23 Stratigos JD \& Katsambas AD. Pellagra: 'A reappraisal'. Acta Vitaminologica et Enzymologica 19824 115-121.

24 Graves K, Kestenbaum T \& Kalivas J. Hereditary acrodermatitis enteropathica in an adult. Archives of Dermatology 1980116 $562-564$.

25 Tanaka S, Yamasaki S, Matsushita H, Ozawa Y, Kurosaki A, Takeuchi K, Hoshihara Y, Doi T, Watanabe G \& Kawaminami K. Duodenal somatostatinoma: a case report and review of 31 cases with special reference to the relationship between tumor size and metastasis. Pathology International $2000 \mathbf{5 0}$ $146-152$.

26 Holst JJ. Enteroglucagon. Annual Review of Physiology 199759 257-271.

27 Drucker DJ. Glucagon and the glucagon-like peptides. Pancreas 19905 484-488.

28 Gillet M, Rodier C, Quencez E, Laurent R, Mantion G, Landecy G, Nguyen N \& Carbillet JP. Pancreatic tumor with diabetes and necrotic migratory erythema. Glucagonoma or proglucagonoma? Chirurgie $1988 \mathbf{1 1 4} 441-446$.

29 Rindi G, Efrat S, Ghatei MA, Bloom SR, Solcia E \& Polak JM. Glucagonomas of transgenic mice express a wide range of general neuroendocrine markers and bioactive peptides. Virchows Archives A Pathological Anatomy and Histopathology 1991419 115-129.

30 Hamid QA, Bishop AE, Sikri KL, Varndell IM, Bloom SR \& Polak JM. Immunocytochemical characterization of 10 pancreatic tumours, associated with the glucagonoma syndrome, using antibodies to separate regions of the pro-glucagon molecule and other neuroendocrine markers. Histopathology $1986 \mathbf{1 0}$ 119-133.

31 Keller U, Fankhauser S, Schumacher A, Trimble ER \& Heitz PU. Glucagonoma syndrome in a multihormonal pancreatic tumor. Schweizerische Medizinische Wochenschrift 1982112 297-304.

32 Almdal TP. Heindorff H. Bardram L \& Vilstrup H. Increased amino acid clearance and urea synthesis in a patient with glucagonoma. Gut 199031 946-948.

33 Barazzoni R, Zanetti M, Tiengo A \& Tessari P. Protein metabolism in glucagonoma. Diabetologia 199942 326-329.

34 Boden G, Rezvani I \& Owen OE. Effects of glucagon on plasma amino acids. Journal of Clinical Investigation 198473 785-793.

35 Tessari P, Inchiostro S, Barazzoni R, Zanetti M, Vettore M, Biolo G, Iori E, Kiwanuka E \& Tiengo A. Hyperglucagonemia stimulates phenylalanine oxidation in humans. Diabetes 199645 463-470.

36 Prendiville JS \& Manfredi LN. Skin signs of nutritional disorders. Seminars in Dermatology $19921188-97$.

37 Larsen PJ, Vrang N \& Tang-Christensen M. Central pre-proglucagon derived peptides: opportunities for treatment of obesity. Current Pharmaceutical Design 20039 1373-1382.

38 Drucker DJ, Boushey RP, Wang F, Hill ME, Brubaker PL \& Yusta B. Biologic properties and therapeutic potential of glucagon-like peptide-2. Journal of Parenteral and Enteral Nutrition 199923 S98-S100.

39 McGregor GP, Goke R \& Goke B. Biological actions of glucagon-like peptide(GLP)-2 revealed - how pluripotential is the glucagon gene? Experimental and Clinical Endocrinology and Diabetes 1998 $10625-28$.

40 Degn KB, Juhl CB, Sturis J, Jakobsen G, Brock B, Chandramouli V, Rungby J, Landau BR \& Schmitz O. One week's treatment with the long-acting glucagon-like peptide 1 derivative liraglutide (NN2211) markedly improves 24-h glycemia and alpha- and beta-cell function and reduces endogenous glucose relaease in patients with type 2 diabetes. Diabetes 200453 1187-1194.

41 Moran TH. Pancreatic polypeptide: more than just another gut hormone? Gastroenterology $2003 \mathbf{1 2 4} 1542-1544$.

42 Asakawa A, Inui A, Yuzuriha H, Ueno N, Katsuura G, Fujimiya M, Fujino MA, Niijima A, Meguid MM \& Kasuga M. Characterization of the effects of pancreatic polypeptide in the regulation of energy balance. Gastroenterology $2003 \mathbf{1 2 4} 1325-1336$.

43 Mullans EA \& Cohen PR. Iatrogenic necrolytic migratory erythema: a case report and review of nonglucagonoma-associated necrolytic migratory erythema. Journal of the American Academy of Dermatology $19983 \mathbf{3 8} 866-873$.

44 Wald M, Lawrenz K, Luckner D, Seimann R, Mohnike K \& Schober E. Glucagon therapy as a possible cause of erythema necrolyticum migrans in two neonates with persistent hyperinsulinaemic hypoglycaemia. European Journal of Pediatrics 2002161 600-603.

45 Case CC \& Vassilopoulou-Sellin R. Reproduction of features of the glucagonoma syndrome with continuous intravenous glucagon infusion as therapy for tumor-induced hypoglycemia. Endocrine Practice $2003922-25$.

Received 23 July 2004

Accepted 26 July 2004 